\title{
UTILIZATION OF LANDSAT-8 DATA FOR LITHOLOGICAL MAPPING OF BASEMENT ROCKS OF PLATEAU STATE NORTH CENTRAL NIGERIA
}

\author{
Danboyi Joseph Amusuk*, Mazlan Hashim, Amin Beiranvand Pour, Sulaiman Ibrahim Musa \\ Geoscience and Digital Earth Centre (Geo-DEC), \\ Research Institute for Sustainability and Environment (RISE), \\ Universiti Teknologi Malaysia, 81310 UTM JB, Malaysia. \\ *Corresponding authors. Email: danboyiamusuk64@gmail.com
}

KEY WORDS: Landsat-8; Plateau State; Lithological Map; Remote Sensing

\begin{abstract}
:
This paper utilized the Landsat-8 image data to map the lithology's of Plateau state north central Nigeria. This is includes the rocks, with particular emphasis on their description and classification. We are living in geologic times and sciences that provide adequate knowledge of the natures of what we live on so as to preserve and have means of sustaining human life. Plateau State is covered by four scenes of Landsat Data, and to describe the lithology's, each scene was processed to produce images. Two different false colour composite images of Landsat-8 (FCC 7, 5 and 3 and BR composites) in RGB were generated and used for the production of 1:100,000 geological map of the study area. The identification of predominant biotitic granitic rocks was revealed and that are distributed along the Jos-Bukuru complex and underlying almost half of the entire state. Moreover, the other rock complexes such as basalts and rhyolites volcanic rocks were also discriminated. This study indicates that Landsat-8 image data has great capability to discriminate lithological units and the production of up-to-date geological maps at regional scale and could be applicable in other regions of the African continent.
\end{abstract}

\section{INTRODUCTION}

The application of remote sensing technique to enable the description, classification and boundaries of surficial features of an area is mapping the lithology. The rationale behind lithological mapping is to broaden knowledge of spectral signatures of a whole range of terrain (Grunsky et al., 2015).

This study can be very useful to mankind because it yields valuable insight into the formation and productivity of soils, agriculture suitability studies, movement of water into aquifers and a lot of important properties of the environment that are influenced by the underlying rocks. Also, it provides the ability to show contact between the lithology's and the mineralogical assemblages. These boundaries could be faults that identifies Hydrothermal and alteration zones or folds that classify the categories of rock types. Bedrock mapping is critical to engineering, construction, and mining operations, and can play a role in land use and urban planning. Understanding the distribution and spatial relationships of these units also facilitates interpretation of the geologic history of the Earth's surface (Pour and Hashim, 2014 a, b).

There are several methods of processing lithologies of an area. Some classify images to discriminate the lithological units using spatial variations and manually draw the boundaries of the features (Van Ruiteenbeck et al., 2008). But this approaches identification and lithological boundaries would not be consistent and are influenced by the interpreters. There are also edge detection algorithm techniques that are used to detect and extract the lithological boundaries using the RTM template matching from the remote sensing imageries, applying Euclidean measures on neighbourhood pixels nevertheless, they also reveal features clearly only when Landsat images are used in conjunction with others such as ASTER images where regions of interests are mapped out for every lithological unit and in addition to field observations.

\section{THE STUDY AREA}

The State has an area of about 26,899, sq.km and shares common boundaries with Benue, Nassarawa, Kaduna, Taraba, Bauchi and Gombe States. The locational map of the state is shown in Figure 1, while the geological map indicates at a small scale the classification of the rock types in Figure 2 respectively.

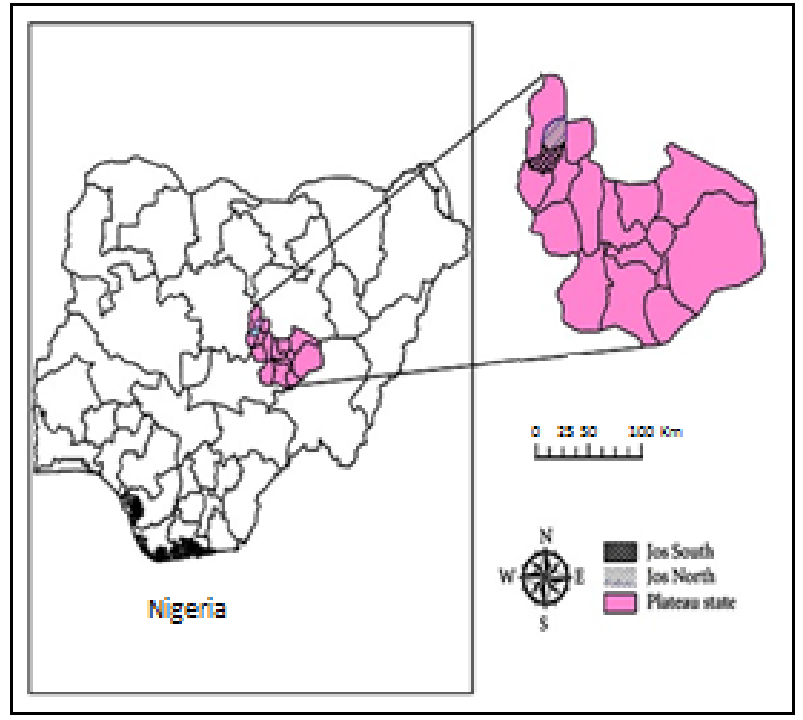

Figure 1. Map of Nigeria showing Plateau state 


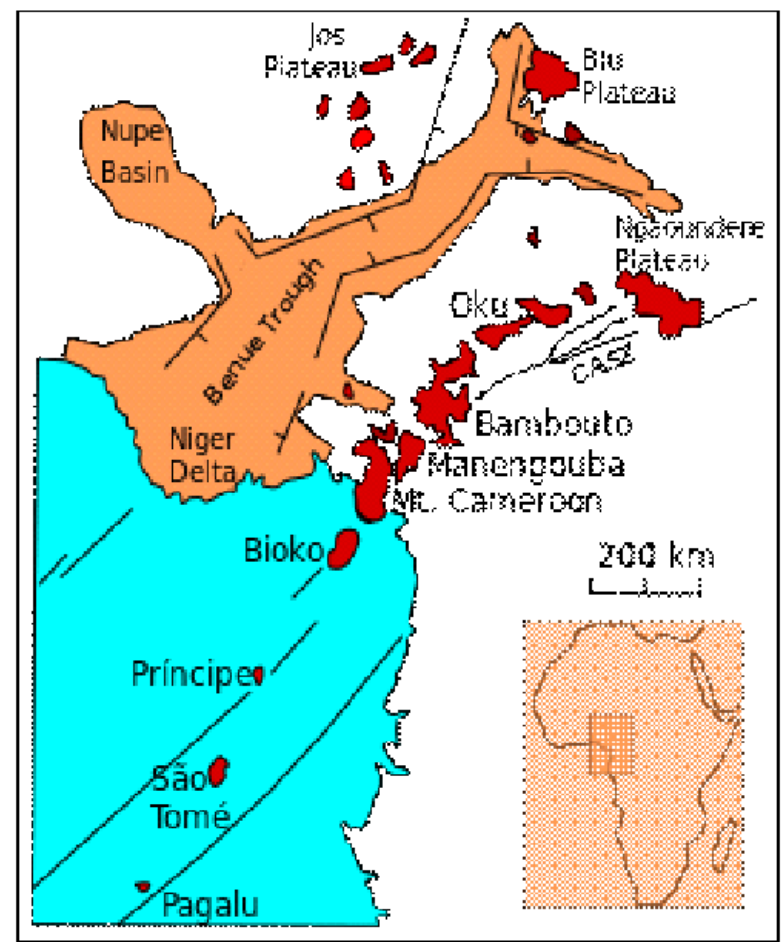

Figure 2: The geological map of Plateau basement rocks.

\section{MATERIALS}

The landsat-8 image data used in this study were downloaded from USGS free download website. The image is suitable by its coverage between both the visible and shortwave infrared waves ranges referred to as multispectral image, where the geologists holds double advantage with them because the shortwave infrared bands in them are sensitive to changes in the soil and rocks content which subsequently make it possible to differentiate some basic rock types. More so, being the first in the series of Landsat sensors to carry alongside a GPS that gives it accurate positioning. The spectral ranges of the sensor are listed below:

Table 1: Spectral characteristics of Landsat-8 image data.

\begin{tabular}{|c|l|c|c|}
\hline S/N & \multicolumn{1}{|c|}{ BAND } & $\begin{array}{c}\text { WAVELENGTH } \\
(\mu \mathrm{m})\end{array}$ & $\begin{array}{c}\text { RESOLUTION } \\
(\mathrm{m})\end{array}$ \\
\hline 1 & $\begin{array}{l}\text { Band 1-Coastal } \\
\text { Aerosol }\end{array}$ & $0.43-0.45$ & 30 \\
\hline 2 & Band 2 - Blue & $0.45-0.51$ & 30 \\
\hline 3 & Band 3 - Green & $0.53-0.59$ & 30 \\
\hline 4 & Band 4 - Red & $0.64-0.67$ & 30 \\
\hline 5 & Band 5 - NIR & $0.85-0.88$ & 30 \\
\hline 6 & Band 6 - SWIR 1 & $1.57-1.65$ & 30 \\
\hline 7 & Band 7 - SWIR 2 & $2.11-2.29$ & 30 \\
\hline 8 & $\begin{array}{l}\text { Band 8 } \\
\text { Panchromatic }\end{array}$ & $0.50-0.68$ & 15 \\
\hline 9 & Band 9 - Cirrus & $1.36-1.38$ & 30 \\
\hline 10 & Band 10 - TIR 1 & $10.60-11.19$ & 100 \\
\hline 11 & Band 11 - TIR 2 & $11.50-12.51$ & 100 \\
\hline
\end{tabular}

The ENVI software was also used to apply the processing steps through radiometric calibration by converting the digital numbers to spectral radiance or also called the exoatmospheric reflectance process.

\section{METHODOLOGY}

The methods performed in this study employs the image processing and analysing geospatial imagery techniques provided by software ENVI 4.8 to carry out the lithological classification on Landsat 8 image. The methodology consists of three steps which are pre-processing, lithological classification, and post-processing

The maps derived in this study were from the digital image processing of the landsat-8 image data through the classification exercise. Different techniques were applied in band Image stacking, image transformation and RGB composites. These were supportive to image interpretation. The processed scene images were exported to ArcGIS for mosaicking. This is because Plateau state is covered by four scenes of the Landsat series, and falls at path $187-188$ and Row 053 - 054 in the latitude and longitude respectively. Each of these scenes was made to pass through image pre-processing and enhancement as they are displayed in figure 3 before they were finally mosaicked together to produce a composite map of the study area shown on figure 4 . And it is upon which the boundary line of the state was superimposed on the mosaicked map to show the delineation of the boundaries of the state to surrounding neighbouring states in Nigeria.

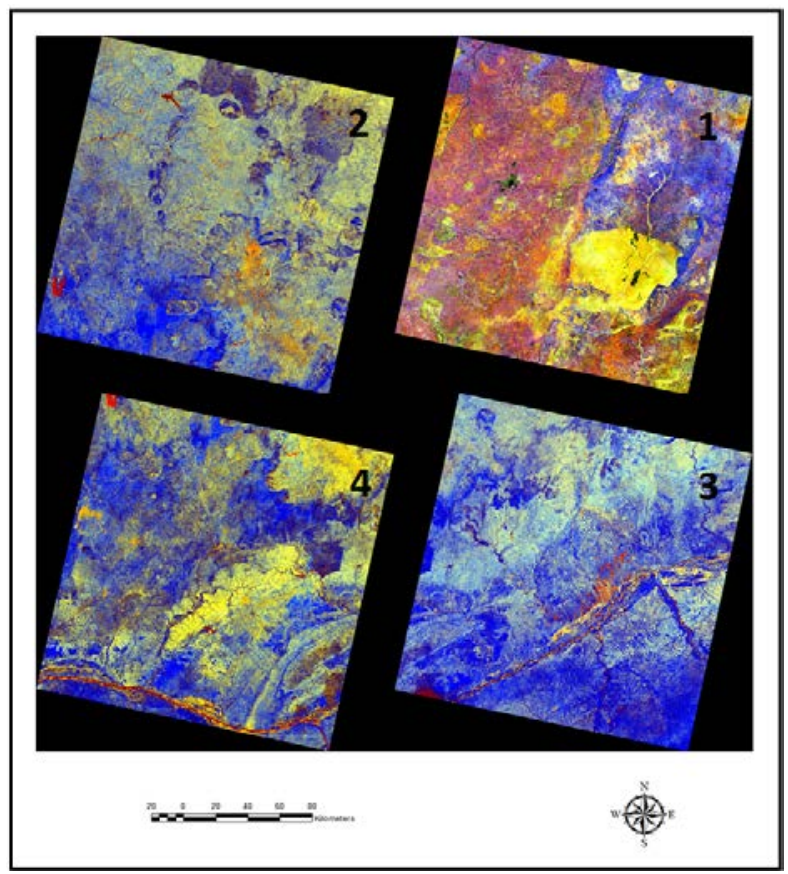

Figure 3. Colour Composites of scenes one, two, three and four.

The mosaicked map of the state reveals a unique geography where the entire plateau is surrounded by its boundary known to be the source of the state's name. There are also scattered bare rock formations around the north that looks captivating and scattered around the grasslands such as the Kahwang rock formation, a basalt rock around the Bachi district, a hillock called Wase Rock that is a striking dome down some distance away from the plateau in the south-eatern part with the shape of an inselberg, known to be a ranch for a specie of Ravens in Africa. There is the Kerang highlands, a volcanic hill that sources the SWAN natural mountain spring and the Shere hills with the highest peak where an abstract composite view of the Jos city capital of the state can be taken. 
The plateau is the source of several rivers that flows to Bauchi, Kaduna, Hadejia, Yobe River and regions of narrow and deep valleys that traverses all the edges of the plateau. Volcanic activities of long time history must be resultant of the old and Younger granitic rocks that are predominant in the Plateau (Official website, 2016). The identification of exposed rocks formation was through the band ratio operation exercise, and the combinations of $7 / 5,6 / 5$ and $2 / 4$ were used and a composite image of the band ratios revealed the existence of varieties of Volcanic and Granitic rocks.

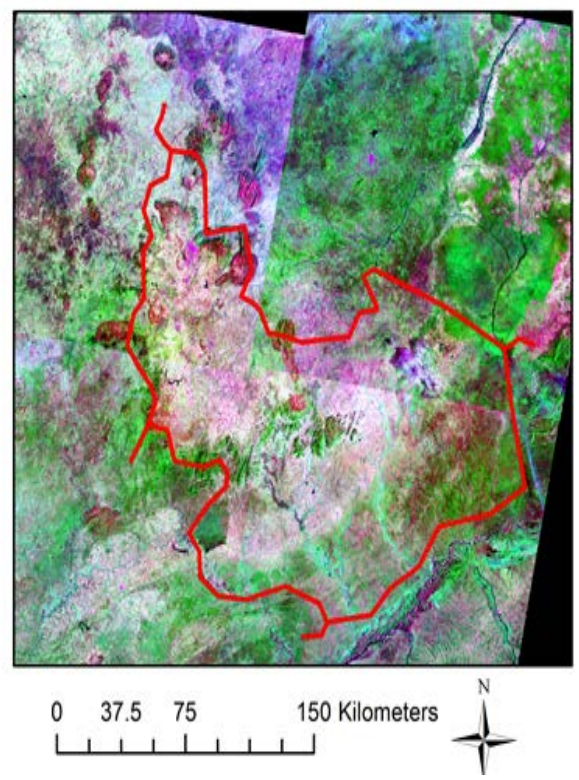

Figure 4. Mosaicked Composites of four scenes and boundary.

\section{DISCUSSION}

The main features that are usually visible in remotely sensed data and DEMs are the faults, shears and fractures as well as the lithological boundaries between different rocks and their level of resistance to erosion. Therefore, Colour composite images for this study area were created to show the classification and distributions of rock types for each image scene, the Near Infrared (NIR) wavelength is one of the most commonly used wavelengths on multispectral sensors because vegetation reflects so strongly in this portion of the electromagnetic spectrum that this information proves very useful when performing vegetation analyses. Each scene was processed through creation of image stack, image pyramid, RGB Composite image creation as follows:

Bands (7, 5 and 3) gave a false colour image composite with an enhanced image with the rocky outcrops shown in shades of purple and blue. Many structural features are visible with good atmospheric penetration, this band combination is similar to the 5, 6, 4 band combination but vegetation shows up in more vibrant shades of green, rock classification and urban areas as well as some kinds of soil to appear as shown in figure (4, 5, 6, and 7). Band 5 measures the near infrared, or NIR. This part of the spectrum is especially important for ecology because healthy plants reflect it - the water in their leaves scatters the wavelengths back into the sky while Bands 6 and 7 cover different slices of the shortwave infrared, or SWIR. They are particularly useful for telling wet earth from dry earth, and for geology: rocks and soils that look similar in other bands often have strong contrasts in SWIR. While band 3 is very useful for discerning differences in bare earth and for telling what is wet and what is dry in a scene. The RGB composites for the four scenes are shown in figures (Pour and Hasim, 2014).

\section{CONCLUSION}

In terrains that have diverse characteristics, it is difficult to isolate all the different kinds of rocks, with a single image product.This study has shown that the Landsat-8 image data is ideal for the regional and early exploration studies in arid and semi-arid regions where there are sparse vegetative coverage. There are certainly several additional band combinations that would be useful for visualizing Landsat 8 scenes. In some situations, loading a grayscale image of a single band might also help to visualize specific features or phenomena. There are many analysis techniques that can be applied to multispectral imagery to extract specific features of interest. These algorithms rely on the same principles of reflectivity and absorption at various wavelengths that allow us to see certain features when visualizing them with different band combinations. An important point to note is that if a particular band, or combination of bands, does a good job of helping you visualize a feature that is of interest to you, then it is highly likely that this band, or combination of bands, can be used to help you isolate that feature from your image

\section{REFERENCES}

David W. Leverington 1,* and Wooil M. Moon, 2012. LandsatTM-Based Discrimination of Lithological Units Associated with the Purtuniq Ophiolite, Quebec, Canada, Remote Sens. 2012, 4, 1208-1231; doi:10.3390/rs4051208

Goward, S., Williams, D., Arvidson, T., Irons, J. 2011. The Future of Landsat-Class Remote Sensing. In Land Remote Sensing and Environmental Change; Ramachandran, B., Justice, C.O., Abrams, M.J., Eds.; Remote Sensing and Digital Image Processing 11, Springer Science and Business Media: Berlin, Germany; pp. 807-834.

Harris, J.R.; Wickert, L.; Lynds, T.; Behnia, P.; Rainbird, R.; Grunsky, E.; McGregor, R.; Schetselaar, E. 2011. Remote predictive mapping 3. Optical remote sensing-A review for remote predictive geological mapping in northern Canada. Geosci. Can., 38, 49-83.

Harris J.R.; Grunsky E.C. 2015. Lithological mapping of Canadas North using random forest classification applied to geophysical and geochemical data. Journal of computer and geosciences, vol 80, issue c pp.9-25

Jens H. 2012. The new global lithological map database GLiM: A representation of rock properties at the Earth surface. G3 an AGU journal. DOI: 10.1029/2012GC004370.

Pour, A.B., Hashim, M. 2014a. The Earth Observing-1 (EO1) satellite data for geological mapping, south eastern segment of the Central Iranian Volcanic Belt, Iran. International Journal of the Physical Sciences, 6(33), 7638-7650.

Pour, A.B., Hashim, M. 2014b. ASTER, ALI and Hyperion data for lithological mapping and ore mineral exploration. SpringerPlus, 3:130

Stephen G., Dickson C., Jonathan K.T, Cohm J. 2013 Lithological mapping using spectral remote sensing: a global feasibility study, GRSG AGM-status and development in Geological remote sensing. 